\title{
DETECÇÃO DE Phamerochaete salmonicolor EM MOGNO AFRICANO NO ESTADO DO PARÁ
}

\author{
LUIZ S. POLTRONIERI, FERNANDO C. ALBUQUERQUE, DINALDO R.TRINDADE, \\ M. LOURDES R. DUARTE, J. EDMAR U. CARVALHO \& CARLOS H. MULLER
}

Embrapa Amazônia Oriental, Cx. Postal 48, CEP 66095-100, Belém, PA, e-mail: poltroni@cpatu.embrapa.br

(Aceito para publicação em 03/04/2002)

Autor para correspondência: Luiz S. Poltronieri

\section{ABSTRACT \\ Detection of Phamerochaete salmonicolor in African mahogany in the State of Pará, Brazil}

Two-year-old plants of African mahogany (Khaya ivorensis) growing at Embrapa Experimental Station in Belém and in the municipalities of Igarapé-Açu and Santa Bárbara have been infected by Phamerochaete salmonicolor, which causes pink disease. Pink disease is recorded for the first time in African Mahogany in the State of Pará, Brazil.
O mogno africano (Khaya ivorensis A. Chev.) tem sido uma das espécies preferidas pelos reflorestadores no estado do Pará. É uma árvore de grande importância para a região amazônica, devido ao seu alto valor econômico e crescimento relativamente rápido, promovendo a recuperação de áreas alteradas (Falesi \& Baena. Embrapa Amazônia Oriental, Documentos $n^{\circ} 4,1999$ ) e sua resistência à broca da ponteira causada por Hypsipyla grandella Zeller (Poltronieri et al. Fitopatol. Bras. 25:204.2000). Na área experimental da Embrapa Amazônia Oriental em Belém, PA e cultivos comerciais nos municípios paraenses de Igarapé- Açu e Santa Bárbara, foram observadas plantas de mogno africano com dois anos de idade apresentando sintomas caracterizados por lesões necróticas de coloração rósea causando depressão e rachadura da casca do tronco e galhos culminando com a formação de uma crosta rosada na superfície dos ramos e troncos infetados. Plantas severamente infetadas apresentavam secamento e morte de galhos. Porções de micélio, retiradas diretamente do material infetado, foram implantados em placas de Petri contendo ágarágua e, após o crescimento de hifas, realizou-se transferência para meio de cultura BDA. Por meio de observações macroscópicas e microscópicas, foi possível identificar como sendo o fungo Phamerochaete salmonicolor Berk \& Broome Jul., conhecido anteriormente como Corticium salmonicolor (Berk \& Broome), agente causal da rubelose ou mal rosado. Phamerochaete salmonicolor apresenta basidiomas efusos, com himênio exposto revestido de basídias claviformes ou cilíndricas com quatro esterigmas, basidiosporos elipsóides de coloração rosada em massa. $\mathrm{O}$ teste de patogenicidade foi realizado mediante a inserção de discos de ágar contendo micélio no caule de mudas de mogno africano com três meses de idade. Logo após a inoculação, as mudas foram mantidas em câmara úmida por um período de $72 \mathrm{~h}$. Nas testemunhas foram inseridos apenas discos de ágar. $\mathrm{O}$ aparecimento dos sintomas ocorreu a partir do $7^{\circ}$ dia após a inoculação. Reisolamento obtido das plantas inoculadas apresentaram as mesmas características das culturas originais, comprovando ser $P$. salmonicolor o agente causal da doença. A rubelose já foi constatada no estado do Pará afetando pimenta-do-reino (Piper nigrum L.) [Albuquerque \& Duarte. Corr. Agríc. (2/3):114-119.1977], seringueira (Hevea spp.) [Gasparotto et al. Embrapa- CNPSD, Circular Técnica, $n^{\circ} 4$, 1984] e citros (Citrus spp.) (Ribeiro, S.I. Citrus. Embrapa/Uepae de Belém, Documentos, $\mathrm{n}^{\circ} 10$, 1989). Este é o primeiro relato da ocorrência de P. salmonicolor afetando plantas de mogno africano no Brasil.

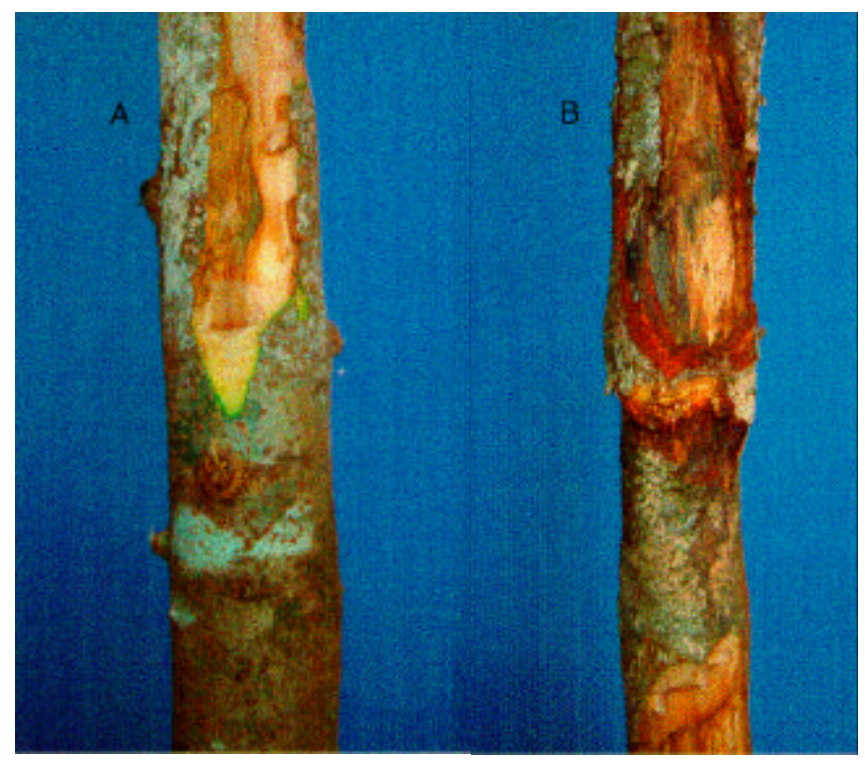

FIG. 1 - Sintomas de rubelose em mogno africano (Khaya ivorensis) causados por Phamerochaete salminicolor. A - estágio inicial; B - estágio final. 